6 Bek T. Coexistence of localized scotomata and neovascularizations in proliferative diabetic retinopathy. Acta Ophthalmol 1990; 68: 421-7.

7 Bek T, Lund-Anderson H. Localised blood-retinal barrier leakage and retinal light sensitivity in diabetic retinopathy.

8 Bek T, Lund-Anderson H. Cotton-wool spots and retinal light sensitivity in diabetic retinopathy. Br f Ophthalmol 1991, 75: 13-7.

9 Trick GL, Trick LR, Kilo C. Visual field defects in patients with insulin-dependent and noninsulin dependent diabetes. Ophthalmology 1990; 97: 475-82.

10 Bell JA, Feldon SE. Retinal microangiopathy: correlation of
OCTOPUS perimetry with fluorescein angiography. Arch Ophthalmol 1984; 102: 1294-8.

11 Engerman RL, Dern TS. Progression of incipient diabetic retinopathy during good glycaemic control. Diabetes 1987; 36: 808-12.

12 Hamilton AM, Townsend C, Khoury D, Gould E, Blach RK Xenon arc and argon laser photocoagulation in the treatmen of diabetic disc neovascularization part 1: effect on disc vessels, visual fields and visual acuity. Trans Ophthalmol Soc UK 1981; 101: 87-92.

13 Blankenship GW. A clinical comparison of central and peripheral argon laser panretinal photocoagulation for proliferative diabetic retinopathy. Ophthalmology 1981; 95: 170-7.

History of ophthalmology

\title{
After Helmholtz
}

Helmholtz's revelation of the ophthalmoscope in 1851 provoked a flood of debate in the literature.

James Dixon, of the London Ophthalmological Hospital feared that intense light could 'irreparably damage' the normal retina. He thus cautioned against indiscriminate funduscopy, advising students to first practise on kittens (the prospect of generations of blind cats obviously left him unmoved). Only then could they practise on patients 'who had long been hopelessly blind.' One infers a certain lack of confidence in his trainees.

It was soon realised that funduscopy would be useful to general physicians, who apparently had even more trouble than ophthalmologists in performing it. Many discarded the apparatus in frustration and condemned the technique. 'All too often,' bemoans Dr Solomon, 'after repeated trials the instrument is put aside as an instance of 'non possumus' - Latin for 'it doesn't work.' Considering the instructions of the time, one can regard this view with sympathy.

Soelberg Wells advocates first placing a lamp in close proximity to the patient's ear. With the right hand, a circular mirror is held and adjusted to reflect the light from the flame into the eye, 'so that it glows brilliant red,' while with the left hand, a biconvex lens is held two inches before the eye. The left ring finger should rest on the orbital margin, and the little finger be employed in raising the lid. 'Practice and perseverance' were necessary.

Even the lamp's construction was debated. Soelberg Wells magnanimously admitted that the best lamp was Moorfields (he was a King's man), which was a porcelain burner closed by fine gauze to steady the flame. The mirror's surround was the focus of oneupmanship - most opted for ivory or silver, but Hogg had his mounted in tortoiseshell and reported the fact in the journals.

Dixon believed a blue glass lamp would decompose red rays to make visualisation easier, and this may have narrowly missed becoming the ophthalmologists' equivalent of the barber's red stripe. More simply, Wilson used sunlight for funduscopy - when there was any - by the simple expedient of having the local carpenter cut a circular hole in his shutters. (These problems disappeared after 1884 with the advent of electrical ophthalmoscopes.)

Dr Williams of Cincinnati insisted that effective restraint of the patient was imperative. He advocated 'wearing one's ophthalmoscope' in the form of large round mirrors with central holes mounted in a spectacle frame. This would certainly leave the hands free, but the resultant appearance of the doctor would do little to calm the very young or mentally impaired subject.

Use of atropine was already accepted (remember there was no possibility of these patients driving themselves home!) but Solomon went one step further in advising the trainee to paralyse his own accommodation too!

Eventually the technique developed into a fine art, and teaching aids had their part to play. 'Perrin's artificial eye' was a brass contraption with a plano convex lens, a black pupil with a variable size perforation, and a posterior aperture into which papier mâché discs, painted to resemble abnormal fundi, could be inserted.

There must have been a moment of amazement for these nineteenth century ophthalmologists, as they, perhaps disbelieving early reports, saw the retina clearly for the first time. Sadly, this is largely submerged beneath the flood of argument. Spencer Wells alone records the sense of excitement, saying, 'the appearance of the vessels on the illuminated base is really beautiful.'

FIONA ROMAN

Dixon J. The ophthalmoscope. In: Braithwaite's retrospect of medicine. London: Simpkin and Co, 1853; XXXII: 284-68. Hogg J. The ophthalmoscope. In: Braithwaite's retrospect of medicine. London: Simpkin and Co, 1857; XXXV: 188-90. McMullen WH. The evolution of the ophthalmoscope BrF Ophthalmol 1917; 1: 593-600.

Soelberg Wells J. Use of the ophthalmoscope. In: Braithwaite's retrospect of mecidine. London: Simpkin and Co, 1871; LXIII 218-22.

Spencer Wells T. In: Braithwaite's retrospect of medicine. London: Simpkin and Co, 1854; XXIX: 368-71. 